\title{
Enhancing the immunogenicity of tumour lysate-loaded dendritic cell vaccines by conjugation to virus-like particles
}

\author{
SJ Win ',2, DGG McMillan ${ }^{3}$, F Errington-Mais², VK Ward', SL Young ${ }^{4}$, MA Baird' and AA Melcher,2 \\ 'Department of Microbiology and Immunology, Otago School of Medical Sciences, University of Otago, Dunedin, New Zealand; ${ }^{2}$ Division of Oncology, \\ Leeds Institute of Molecular Medicine, University of Leeds, Wellcome Trust Brenner Building, Leeds LS9 7TF, UK; ${ }^{3}$ Institute of Membrane and Systems \\ Biology, Faculty of Biological Sciences, University of Leeds, Leeds, UK; ${ }^{4}$ Department of Pathology, University of Otago, Dunedin, New Zealand
}

BACKGROUND: Tumour cell lysates are an excellent source of many defined and undefined tumour antigens and have been used clinically in immunotherapeutic regimes but with limited success.

METHODS: We conjugated Mel888 melanoma lysates to rabbit haemorrhagic disease virus virus-like particles (VLP), which can act as vehicles to deliver multiple tumour epitopes to dendritic cells (DC) to effectively activate antitumour responses.

RESULTS: Virus-like particles did not stimulate the phenotypic maturation of DC although, the conjugation of lysates to VLP (VLP-lysate) did overcome lysate-induced suppression of DC activation. Lysate-conjugated VLP enhanced delivery of antigenic proteins to DC, while the co-delivery of VLP-lysates with OK432 resulted in cross-priming of naïve $T$ cells, with expansion of a MARTI ${ }^{+}$population of $\mathrm{CD}^{+}{ }^{+} \mathrm{T}$ cells and generation of a specific cytotoxic response against Mel888 tumour cell targets. The responses generated with VLPlysate and OK432 were superior to those stimulated by unconjugated lysate with OK432.

CONCLUSION: Collectively, these results show that the combination of VLP-lysate with OK432 delivered to DC overcomes the suppressive effects of lysates, and enables priming of naïve $T$ cells with superior ability to specifically kill their target tumour cells. British Journal of Cancer (2012) I 06, 92-98. doi:I0.1038/bjc.20II.538 www.bjcancer.com

Published online I December 201 I

(c) 2012 Cancer Research UK

Keywords: VLP; tumour immunotherapy; lysate therapy

Immunotherapy of melanomas is an area of great current clinical interest, owing to the immunogenic nature of melanomas and the identification of many defined tumour antigens (Kawakami et al, 1994; Romero et al, 2002). Many therapeutic strategies have centred around the activation of cytotoxic T lymphocytes (CTLs) to produce high levels of IFN- $\gamma$ and specific cytolytic activity. Strategies for inducing tumour-specific CTL in vivo have utilised adjuvant-activated dendritic cells (DC) pulsed with melanoma peptides or tumour lysates, either delivered directly to patients or used for ex vivo activation of autologous $\mathrm{T}$ cells for adoptive transfer (Dudley et al, 2005; Fang et al, 2008). Although these approaches have been used in clinical trials, they have yielded modest benefits for patients to date, suggesting that modifications to these strategies may improve the specificity and potency of antitumour immune responses (Hershey et al, 2002; Salcedo et al, 2006; Hong et al, 2010).

The use of DC pulsed with tumour lysates and activated with an adjuvant is thought to result in limited responses because of the induction of tolerance in the context of DC-tumour interactions (Mehrotra et al, 2003). This may in part be due to the inhibitory nature of lysates on the concomitant activation of DC as, for example, DC pulsed with lysates and matured with the potent bacterial adjuvant OK432 have been shown to secrete less cytokines and have lower expression of MHC-II and costimulatory

*Correspondence: Professor AA Melcher; E-mail: a.a.melcher@leeds.ac.uk Received 2 August 2011; revised 8 November 2011; accepted 10 November 201 I; published online I December 20 I I molecules than unpulsed DC matured with OK432 (Hatfield et al, 2008).

Virus-like particles (VLP) are a candidate vaccine with the potential to enhance the immunogenicity of tumour lysate proteins, as they can act as vehicles for the delivery of heterologous antigens to DC, leading to the generation of strong cytotoxic T-cell responses (Storni et al, 2004; Qiao et al, 2006). Virus-like particles are formed from viral capsid proteins and are stable, non-replicative and highly immunogenic, making them a safe option for the treatment of cancer patients. Model tumour antigens either chemically coupled to rabbit haemorrhagic disease virus virus-like particles (RHDV VLP) or recombinantly expressed within the particles, have shown strong efficacy in vivo using murine models of melanoma (Peacey et al, 2008).

Previous studies have demonstrated that RHDV VLP conjugated to tumour lysates are cross-presented by human DC to induce strong $\mathrm{CD}^{+}$T-cell responses in vitro, although, murine DC have shown no evidence of activation by VLP (Win et al, 2011). Crosspresentation of tumour antigens is an important prerequisite for the development of activated $\mathrm{T}$ cells with cytotoxicity against tumour cells, although DC induce more potent cytotoxic T-cell responses when they have been optimally matured (Storni et al, 2002; Keller et al, 2010).

Here, we demonstrate that VLP conjugated to tumour cell lysates are able to induce specific immune responses towards tumour cells, while negating the inhibitory effects of lysates delivered alone. This is achieved through enhanced delivery of antigen and cross-presentation capabilities of DC, and is further dependent on the addition of an adjuvant to ensure effective DC maturation and priming of naïve $\mathrm{T}$-cell responses. 


\section{MATERIALS AND METHODS}

\section{Generation and coupling of Mel888 lysates to VLP}

Conjugation of Mel888 tumour cell lysates to RHDV VLP was carried out as previously described (Peacey et al, 2007; Win et al, 2011). Mel888 tumour cells (Cancer Research UK) were grown in DMEM with $10 \%$ FCS and $1 \%$ L-glutamine and lysates were made by three repeat cycles of freeze-thaw lysis in the presence of complete mini EDTA-free protease inhibitor tablets (Roche Diagnostics Ltd, Mt Wellington, New Zealand). Cells were routinely tested for Mycoplasma and found to be free of infection.

Lysates were mixed with a 10 -fold molar excess of the heterobifunctional linker sulfo-succinimidyl 4 - $(N$-maleimidomethyl $)$ cyclohexane-1-carboxylate (sulfo-SMCC) (Pierce, Rockford, IL, USA) in phosphate buffer $\mathrm{pH} 7.3$ followed by dialysis to remove unbound chemical linker. Virus-like particle were reacted with a 10 -fold molar excess of $N$-succinimidyl $S$-acetylthioacetate (SATA) (Pierce) followed by treatment with $100 \mu \mathrm{g}$ hydroxylamine. $\mathrm{HCl}$ (Sigma, Dorset, UK) per ml of protein. Thiol-activated VLP were passed through a HiTrap desalt column (GE Healthcare, Bucks, UK) to remove unbound SATA. Equal concentrations of thiolactivated VLP and malemide-activated lysates were mixed together for $1 \mathrm{~h}$. Coupling was confirmed using sodium dodecyl sulphatepolyacrylamide gel (SDS-PAGE) containing $10 \%$ or $15 \%$ acrylamide and western blotting using polyclonal rabbit anti-VLP and monoclonal human anti-MART-1 antibodies (clone M2-7C10; Serotec, Oxon, UK).

\section{Preparation of monocyte-derived DCs}

The white blood cell fraction from apheresis blood products (National Blood Service, Leeds, UK) was separated using Lymphoprep (Axis-Shield, Dundee, Scotland, UK) gradients and $\mathrm{CD}^{+} 4^{+}$monocytes were selected with a MACS column using anti-CD14 magnetic beads (Miltenyi Biotec, Surrey, UK). The $\mathrm{CD}_{14}{ }^{+}$cells were cultured for 5 days in RPMI (Sigma) containing $10 \%$ FCS with $800 \mathrm{U} \mathrm{ml}^{-1} \mathrm{GM}-\mathrm{CSF}$ and $500 \mathrm{U} \mathrm{ml}^{-1}$ IL-4 (R\&D Systems, Abingdon, UK) at $37^{\circ} \mathrm{C}+5 \% \mathrm{CO}_{2}$ (Errington et al, 2008).

\section{DC activation}

Dendritic cells were exposed to $50 \mu \mathrm{g} \mathrm{ml}^{-1}$ VLP-Mel888 lysates, Mel888 lysates or left un-stimulated for $4 \mathrm{~h}$ before the addition of $10 \mu \mathrm{g} \mathrm{ml}^{-1}$ OK432 (Chugai Pharmaceutical Co., Ltd, Tokyo, Japan) for $24 \mathrm{~h}$ at $37^{\circ} \mathrm{C}+5 \% \mathrm{CO}_{2}$. Cell staining was performed using anti$\mathrm{CD} 11 \mathrm{c}-\mathrm{APC}$ and PE-conjugated monoclonal antibodies directed against epitopes of CD40, CD80, CD86 and HLA-DR. Dendritic cells were incubated with the respective antibodies or IgG isotype control antibodies and fluorescence was measured using a FACSCalibur (BD Biosciences, Oxford, UK). Supernatants were collected and assayed for the presence of IL-12p70, CCL5, IL-6 and TNF- $\alpha$ by ELISA using matched antibodies (BD Biosciences).

\section{Subcellular fractionation}

Dendritic cells $\left(2 \times 10^{6} \mathrm{ml}^{-1}\right)$ were incubated with VLP, Mel888 lysate or VLP-Mel888 lysate $\left(50 \mu \mathrm{g} \mathrm{ml}^{-1}\right)$ for either 1 or $3 \mathrm{~h}$. After three washes in ice-cold PBS ( $\mathrm{pH}$ 6.8), cell pellets were resuspended in $1 \mathrm{ml}$ homogenisation buffer (HB; PBS, $0.25 \mathrm{~m}$ sucrose, $10 \mathrm{~mm}$ Tris, $1 \mathrm{~mm}$ EDTA with protease inhibitors and DNase (Complete - Roche Diagnostics, Sussex, UK), pH 6.8) and gently homogenised with a cell-cracker (HGM laboratory equipment). Postnuclear supernatant was prepared by centrifugation of crude lysis at $1000 \times \mathrm{g}$ for $10 \mathrm{~min}$ at $4{ }^{\circ} \mathrm{C}$. The supernatant was moved to a new microfuge tube. Light membranes (recycling and early endosomes) were separated from heavy membranes (late endosomes and lysosomes) by centrifugation at $8000 \times \mathbf{g}$ for $20 \mathrm{~min}$ at $4{ }^{\circ} \mathrm{C}$. The post $-8000 \mathrm{~g}$ supernatant was adjusted to $40 \%$ $(\mathrm{w} / \mathrm{v})$ sucrose using a stock of $80 \%(\mathrm{w} / \mathrm{v})$ sucrose in HB to a final volume of $4 \mathrm{ml}$. This was overlayed with a $4 \mathrm{ml}$ volume of $35 \%$ (w/ v) sucrose in $\mathrm{HB}$, followed by a $4 \mathrm{ml}$ volume of $5 \%(\mathrm{w} / \mathrm{v})$ sucrose in HB. Recycling endosomes were separated from early endosomes by ultracentrifugation at $180000 \times \mathrm{g}$ for $16 \mathrm{~h}$ at $4{ }^{\circ} \mathrm{C}$. The top $3 \mathrm{ml}$ was discarded. The next $5 \mathrm{ml}$ (recycling endosomes) was washed with PBS (pH 6.8) and pelleted by ultracentrifugation at $144651 \times \mathbf{g}$ for $2 \mathrm{~h}$ at $4{ }^{\circ} \mathrm{C}$. The last $4 \mathrm{ml}$ from the separation (early endosomes) was washed with PBS ( $\mathrm{pH}$ 6.8) and pelleted by ultracentrifugation at $144651 \times \mathrm{g}$ for $2 \mathrm{~h}$ at $4{ }^{\circ} \mathrm{C}$. The post- $8000 \mathrm{~g}$ pellet was resuspended in $4 \mathrm{ml} \mathrm{HB}$ containing $10 \%$ Percoll and loaded on top of $6 \mathrm{ml}$ of HB containing 45\% Percoll. Late endosomes and lysosomes were separated by ultracentrifugation at $50000 \times \mathrm{g}$ for $1 \mathrm{~h}$ at $4{ }^{\circ} \mathrm{C}$. The top $4 \mathrm{ml}$ (late endosomes) was washed with PBS (pH 6.8) and pelleted by ultracentrifugation at $144651 \times \mathrm{g}$ for $2 \mathrm{~h}$ at $4{ }^{\circ} \mathrm{C}$. The bottom $4 \mathrm{ml}$ (lysosomes-late endosome fusions) was washed with PBS (pH 6.8) and pelleted by ultracentrifugation at $144651 \times \mathrm{g}$ for $2 \mathrm{~h}$ at $4{ }^{\circ} \mathrm{C}$.

\section{SDS - PAGE and immunoblotting}

Cellular fractions were routinely analysed on $12.5 \%$ SDS - PAGE in the presence of $0.1 \%$ SDS using the buffer system of Laemmli (1970). Polypeptide bands were visualised using Simply Blue Safe Stain (Invitrogen, Paisley, UK). During immunoblotting, membrane vesicles were subjected to $12.5 \%$ SDS-PAGE followed by electroblotting onto a polyvinylidene difluoride membrane including $0.02 \%$ SDS in the running buffer. Cell fractions were probed using rabbit-derived serum against RHDV-VLP and antibodies against MART1 (Serotec), LAMP-1 (clone 25, BD Biosciences), EEA1 (clone 14, BD Biosciences), Rab11 (clone 47, BD Biosciences) and Rab7 (clone 117, Abcam, Cambridge, UK). Horseradish peroxidase-conjugated goat-derived anti-mouse secondary antibody was used for detection (Invitrogen). The antibody-specific bands were visualised using the SuperSignal West Pico chemiluminescence system (Pierce).

\section{Protein assay}

Protein concentrations were determined using a bicinchoninic acid protein assay kit (Sigma) with bovine serum albumin as the standard.

\section{Naïve T-cell priming}

HLA-A2 ${ }^{+}$DC $\left(1 \times 10^{6}\right.$ cells $\left.\mathrm{ml}^{-1}\right)$ were harvested and pulsed with $50 \mu \mathrm{g} \mathrm{ml}^{-1}$ VLP, Mel888 lysate or VLP-Mel888 lysate for $4 \mathrm{~h}$ before the addition of $10 \mu \mathrm{g} \mathrm{ml}^{-1}$ OK432 overnight. The DC were washed and cultured with PBMC at a ratio of 15-40:1 (PBMC:DC) in CTL media (RPMI with $1 \%$ non-essential amino acids, $1 \%$ L-glutamine, $1 \%$ sodium pyruvate, $1 \%$ HEPES, $20 \mu \mathrm{m} 2$-mercaptoethanol and $7.5 \%$ human serum (Sigma)) containing $10 \mu \mathrm{g} \mathrm{ml}^{-1}$ IL-7 (R\&D Systems) for 7 days at $37^{\circ} \mathrm{C}+5 \% \mathrm{CO}_{2}$. After 4 days, $30 \mathrm{U} \mathrm{ml}^{-1}$ of IL-2 (R\&D Systems) was added to the CTL cultures. After 7 days, fresh DC pulsed with VLP, Mel888 lysate or VLP-Mel888 lysate were added and cultured for a further 7 days. The CTL were then assessed for their specificity and cytotoxic activity against Mel888 target cells with ovarian tumour cells, SKOV-3, used as irrelevant target cells.

\section{MART1 pentamer staining}

CTL $\left(1 \times 10^{6}\right.$ cells $)$ were labelled with APC-conjugated ELAGIGILTV pentamer (F082-4A, ProImmune, Oxford, UK), FITC-conjugated anti-CD8 and PE-conjugated anti-CD19 antibodies or respective IgG isotype controls (BD Biosciences). The cells were analysed by flow cytometry. 
94

\section{Cytotoxicity assay}

T-cell cytotoxicity was measured by ${ }^{51} \mathrm{Cr}$ release where target cells $\left(5000\right.$ cells per well) were labelled with $100 \mu \mathrm{Ci}{ }^{51} \mathrm{Cr}$ (Perkin Elmer, Cambridge, UK) for $1 \mathrm{~h}$ then washed three times in RPMI containing 10\% FCS and 1\% L-glutamine. Labelled cells were then incubated with cold Daudi cells ( 5000 cells per well, to quench nonspecific killing) and CTL at different effector:target ratios. After $4 \mathrm{~h}$, the cells were pelleted and $50 \mu \mathrm{l}$ of supernatant was transferred to scintillation plates (Perkin Elmer) and left to dry overnight. Levels of ${ }^{51} \mathrm{Cr}$ were measured in the supernatants using a Wallac Jet 1459 Microbeta Scintillation counter and Microbeta Windows software (Perkin Elmer).

Percent specific lysis was calculated by the following formula:

$$
\begin{aligned}
\% \text { specific lysis }= & (\text { sample c.p.m. }- \text { spontaneous c.p.m. }) \\
& /(\text { maximum c.p.m. }- \text { spontaneous c.p.m. }) \times 100
\end{aligned}
$$

\section{CD107 and IFN- $\gamma$ release}

Cytotoxic T lymphocytes $\left(2.5 \times 10^{5}\right.$ cells $)$ were cultured with target cells at a $1: 1$ ratio for $1 \mathrm{~h}$ at $37^{\circ} \mathrm{C}$ before the addition of FITCconjugated anti-CD107a and CD107b antibodies (BD Biosciences), and $10 \mu \mathrm{g} \mathrm{ml}^{-1}$ brefeldin A (Sigma) or $10 \mu \mathrm{g} \mathrm{ml}^{-1}$ brefeldin A only. The cells were incubated for a further $4 \mathrm{~h}$ before co-staining with PerCP-conjugated anti-CD8 antibodies (BD Bioscences) for $30 \mathrm{~min}$. The CD107a/b-labelled cells were fixed in $1 \%$ paraformaldehyde (Sigma) and analysed by flow cytometry while the additional set were stained for intracellular IFN- $\gamma$ (BD Bioscences). These cells were fixed in $1 \%$ paraformaldehyde before permeabilising in $0.3 \%$ saponin (Sigma) for $30 \mathrm{~min}$ and stained with FITC-conjugated anti-IFN $-\gamma$. The cells were washed and analysed immediately by flow cytometry.

\section{Statistical analyses}

Student's two-tailed paired $t$-tests were performed where statistics are shown using GraphPad Prism version 5.0b (La Jolla, CA, USA). Significance was assigned where $P$-values were 0.05 or less.

\section{RESULTS}

RHDV VLP require the addition of an adjuvant to mature DC, although conjugation of tumour cell lysates to VLP overcomes the inhibitory effects of lysates on DC maturation

Activation of cytotoxic T-cell responses requires $\mathrm{DC}$ to deliver antigen-specific signals to T cells by way of MHC-I:peptide ligation of the TCR, while also providing costimulatory molecule engagement and secretion of appropriate cytokines. Only upon maturation, or activation, do DC provide the necessary levels of costimulation and cytokines to induce activation and expansion of their cognate T cells (Mescher et al, 2006).

Previous studies demonstrated that RHDV VLP do not result in the phenotypic activation of DC in vitro, so we also included an adjuvant to enhance the antigen presentation capacity of VLPlysate-loaded DC. OK432 was chosen as a suitable adjuvant, as it has been shown to activate human monocyte-derived DC and is licensed for clinical use (Hovden et al, 2011). OK432 is a preparation of a penicillin-killed, low virulence strain of streptococcus pyogenes (group A) and has been used as an immunotherapeutic agent in a number of malignancies without significant clinical side effects. The antitumour effects of OK432 are thought to be mediated by the activation of a variety of effector cells, presumably including DC (Kuroki et al, 2003).
Human DC were pulsed with VLP conjugated to Mel888 lysates (VLP-lysate) or lysates, either alone or with OK432 before staining for surface markers of activation (Figure 1) and determining the cytokine secretion profiles of these cells (Figure 2).

Dendritic cells pulsed with VLP-lysate or lysates without adjuvant did not activate DC to increase expression of MHC-II, CD40, CD80 or CD86, nor did they induce secretion of the proinflammatory cytokines IL-12, IL- 6 and TNF- $\alpha$ or the chemokine CCL5. Conversely, the addition of OK432 induced clear increases in MHC-II and costimulatory molecules on the surface of the DC, while also inducing high levels of proinflammatory cytokine and CCL5 secretion.

Interestingly, lysates delivered with OK432 resulted in decreased MHC-II and costimulatory molecule expression and cytokines compared with DC pulsed with OK432 alone. We have previously found this inhibitory effect of lysates on adjuvant-induced activation of DC in both murine and human systems (Hatfield et al, 2008; unpublished data). However, this inhibition was not seen when VLP were conjugated to the lysates, suggesting that the inhibitory effects of lysates on adjuvant-induced activation of DC is reversed by the presence of VLP.

\section{Conjugation of tumour cell lysates to VLP enables more efficient delivery of tumour antigens to DC compartments} for processing

One of the requirements of successful tumour immunotherapy is ensuring efficient delivery of therapeutic antigens to DC in a manner resulting in epitope presentation conducive to the development of cytotoxic T-cell responses. Previous studies have demonstrated that immunogenic peptides or tumour cell lysates conjugated to VLP are cross-presented to $\mathrm{CD} 8^{+} \mathrm{T}$ cells by DC more effectively than peptide or lysates delivered alone; however, the reasons underpinning this effect are not well defined (Win et al, 2011). To further understand the efficiency of antigen
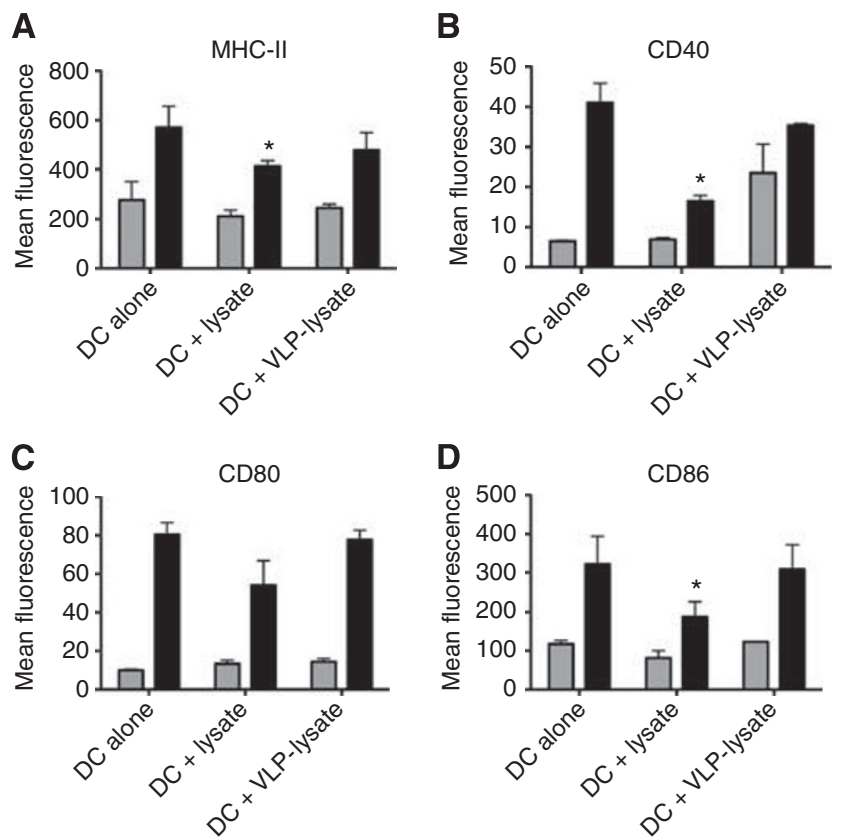

Figure I Conjugation of tumour lysates to VLP negates their inhibitory effects DC phenotypic maturation. Bar graphs represent (A) MHC-II, (B) CD40, (C) CD80 and (D) CD86 expressed on DC alone or pulsed with Mel888 Lysates (Lysate) or VLP-Mel888 Lysates (VLP-Lysate) 4 h prior to the addition of no adjuvant (grey bars) or OK432 (black bars) for $24 \mathrm{~h}$. Data represents mean \pm SD for 6 individual donors. *Denotes statistical significance $(P<0.05)$ between lysate-pulsed and unpulsed DC. 

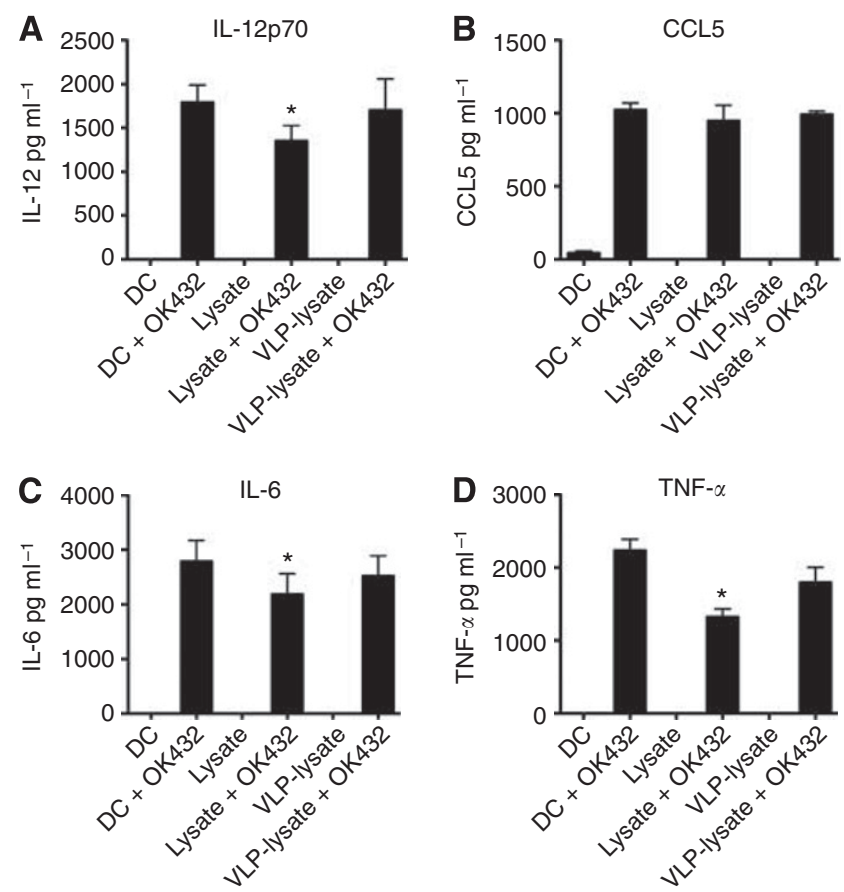

Figure 2 Conjugation of tumour lysates to VLP negates their inhibitory effects on DC cytokine/chemokine production. Bar graphs represent $(\mathbf{A})$ IL-12p70, (B) CCL5, (C) IL-6 and (D) TNF- $\alpha$ produced by DC after pulsing with lysate, VLP-lysate or left unpulsed, before the addition of OK432 or no adjuvant. Data represent mean \pm s.d. for six experiments. *Denotes statistical significance $(P<0.05)$ between lysate-pulsed and unpulsed DC.

delivery and the intracellular trafficking of these antigens, DC pulsed with lysates, VLP or lysates conjugated to VLP were fractionated into their constituent subcellular compartments and probed for the presence of VLP or lysate.

To confirm the subcellular compartments, an initial DC fractionation was carried out separating early endosomes (EE), late endosomes (LE), lysosomes (Lys) and recycling endosomes (RE) into discrete compartments (Figure 3A). Western blot analysis identified a single band for each of EEA1, Rab7, LAMP1 or Rab11, defining the EE, LE, Lys and RE compartments respectively.

Dendritic cells were then pulsed with VLP, VLP-lysate or lysate alone for 1 or $3 \mathrm{~h}$, and washed to remove excess antigen. The DC were subjected to fractionation into their constituent subcellular compartments and probed by western blot for the presence of the VLP VP60 protein or the Mel888 lysate protein MART1 (Figures $3 \mathrm{~B}-\mathrm{D})$. The resultant blots show that VLP were delivered effectively to DC, as entire VP60 protein was present in EE, LE and Lys, but not RE, after both 1 and $3 \mathrm{~h}$. Interestingly, no MART1 was detected in any of the endosomal fractions at either time point when lysates delivered alone were the source of antigen; however, MART1 from VLP-conjugated lysates was detected in large molecular weight complexes at both 1 and $3 \mathrm{~h}$ after delivery to DC. MART1 was present in both EE and LE, and to a lesser degree Lys, at both time points. Additionally, at $1 \mathrm{~h}$ a small band of $20-30 \mathrm{kDa}$ was seen in the lysosomal fraction, indicating degradation of the higher molecular weight MART1-containing complexes into single MART1 molecules. It is likely that reduced amounts of protein being detected in Lys, and none in RE, is due to degraded forms of the VP60 or MART1 proteins being undetectable by their antibodies. These results indicate that conjugation of lysates to VLP enables more efficient delivery and retention of the antigenic
A
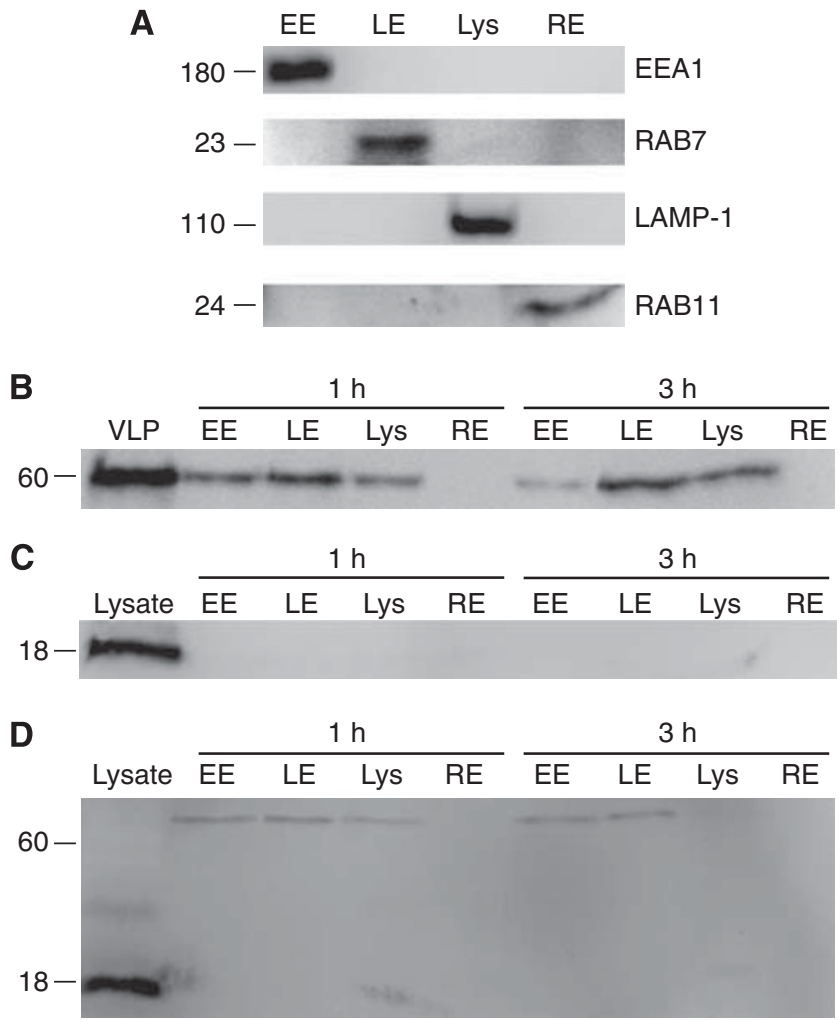

Figure 3 Conjugation of lysates to VLP enhances delivery of tumour antigens to DC antigen processing compartments. (A) Subcellular fractions containing early endosomes (EE), late endosomes (LE), lysosomes (Lys) or recycling endosomes (RE) were prepared from DC. The following probes were used as markers of specific subcellular compartments; EEAI (EE), Rab7 (LE), LAMPI (Lys) and RablI (RE). (B) Dendritic cells were incubated with VLP for I or $3 \mathrm{~h}$. After washing, subcellular fractions were prepared and the presence of VLP was analysed by western blot using antiVP60 antibodies. (C) Dendritic cells were incubated with lysate for I or $3 \mathrm{~h}$. After washing, subcellular fractions were prepared and the presence of MARTI was analysed by western blot. (D) Dendritic cells were incubated with VLP-lysate for I or $3 \mathrm{~h}$. After washing, subcellular fractions were prepared and the presence of MARTI was analysed by western blot. Results are representative of four independent experiments.

proteins in antigen processing compartments by DC, than lysates delivered alone.

Delivery of VLP conjugated to tumour cell lysates together with an adjuvant enables cross-priming of naïve CD8 $\mathrm{T}$-cell responses

Activation and expansion of $\mathrm{T}$ cells expressing TCRs specific for melanoma antigens from circulating naïve $\mathrm{T}$ cells is essential for achieving adaptive cytolytic activity against tumour cells, while ensuring that tumour cells are the exclusive targets of any stimulated CTL. Activating CTL against one melanoma epitope, using single peptide therapies, can achieve significant death of target tumour cells, but can also lead to tumour escape whereby tumour cells that do not express that specific antigen continue to grow (Sanchez-Perez et al, 2005). Thus, it is desirable to incorporate many tumour antigens into a DC-based vaccine, so CTL that recognise diverse tumour epitopes can be activated and expanded to prevent tumour escape. To achieve this, VLP conjugated to Mel888 tumour cell lysates or lysates alone were pulsed onto DC with the adjuvant OK432, or with no maturation stimulus and used to prime naïve $\mathrm{T}$-cell responses 
against Mel888 tumour cells using established methodology (Errington et al, 2008).

To determine the expansion of CTL toward a defined melanoma antigen, the primed cells were stained with a MART-1 pentamer. This demonstrated that antigen-specific $\mathrm{T}$ cells were successfully expanded when VLP-lysate or lysates were pulsed onto DC with OK432 (Figure 4). The use of VLP-lysate with OK432 led to greater expansion of MART1-specific $\mathrm{T}$ cells than loading DC with unconjugated lysates and OK432. Moreover, VLP-lysate/OK432 primed a population of CTL able to specifically degranulate against, produce IFN- $\gamma$ on recognition of, and directly lyse Mel888 tumour cells to a greater degree than unconjugated lysates/OK432 (Figure 5). Interestingly, the amount of unconjugated lysate pulsed on to DC $\left(50 \mu \mathrm{g} \mathrm{ml}^{-1}\right)$ was the same amount as total VLP-lysate added where VP60 protein constitutes at the very least half of the total protein delivered. Although it is not well defined exactly which proteins are bound to the VLP, it is likely that the efficiency of this coupling and size constraints limit conjugation of lysate proteins, such that lysate delivered on VLP equates quantitatively to less tumour antigenic protein than pulsing DC with unconjugated lysate by at least half. This suggests that VLP-lysates are particularly efficient at delivering antigens to DC for crosspresentation to T cells.

\section{DISCUSSION}

Virus-like particles carrying tumour antigens are able to improve the survival and delay the growth of tumours in mice with concomitant in vivo cytotoxicity (Peacey et al, 2008). However, it is crucial to translate these findings into human systems to further understand how human immune cells may interact with VLP to generate cytotoxic responses effective in melanoma patients.

Dendritic cells pulsed with VLP conjugated to tumour lysates did not result in phenotypic activation or proinflammatory cytokine secretion above the levels seen with unpulsed DC. This may be due to the lack of nucleic acid within the VLP acting as a pathogenassociated molecular pattern used by cells to recognise viruses through ligation of pattern recognition receptors. However, the addition of an adjuvant, streptococcal-derived OK432, induced maturation of DC with secretion of the proinflammatory cytokines that favour the development of a Th1, cytotoxic immune response. Consistent with current literature in a murine model (Hatfield et al, 2008), the use of lysates derived from tumour cells by way of freeze and thaw cycles was shown to be inhibitory to DC, an effect that is only partially restored with the addition of a maturation
A

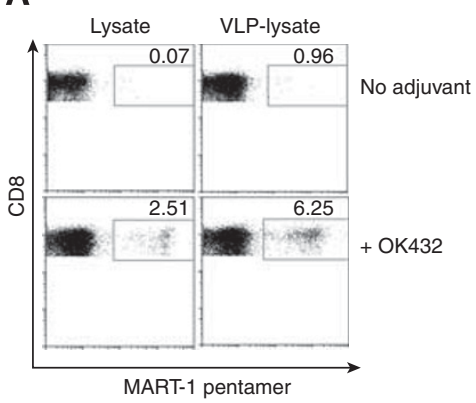

B

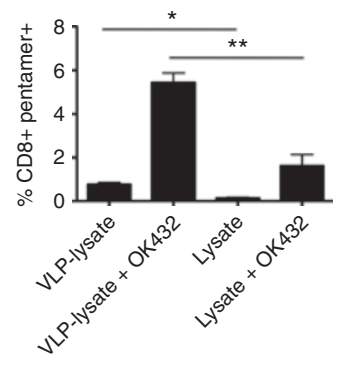

Figure 4 Expansion of MARTI-specific $T$ cells following successive rounds of priming with VLP-lysate or lysate in the presence or absence of adjuvant. (A) Plots demonstrate $\mathrm{CD} 8^{+} \mathrm{T}$ cells expressing a T-cell receptor specific for MARTI from one representative experiment. (B) Bars represent mean \pm s.d. for six experiments. $*$ and $* *$ denotes statistical significance $(P<0.05$ and $<0.0 \mathrm{I})$ between VLP-lysate or lysate-primed CTL without or with OK432. stimulus (note in Figures 1 and 2 the reduced activation of DC by OK432 in the presence, compared with the absence, of lysate). However, the mechanism(s) responsible for this lysate inhibition have yet to be fully elucidated. It has been disputed whether a particular mode of cell death will lead to immune cell activation or suppression, with many reports suggesting that necrotic cell death, similar to that seen when preparing lysates by freeze thaw, is more stimulatory than apoptosis (Strome et al, 2002; von Euw et al, 2007; Herzog et al, 2011). One factor missing from the 'necrotic' cell death induced by freeze - thaw lysis, however, is the induction of stress related molecules such as heat shock proteins, which can act as danger signals for immune activation (Flohe et al, 2003; Bendz et al, 2007; Aguilera et al, 2011). Therefore, the inhibitory nature of lysates may be an inevitable consequence of their method of preparation, although lysates remain highly practical as a source of multiple tumour-associated antigens for clinical application.

Interestingly, the delivery of tumour cell lysates conjugated to VLP, in contrast to unconjugated lysate, did not reduce the ability of DC to activate in the presence of OK432. There are two possible explanations for this observation. First, tumours contain many immunosuppressive molecules, which may not be preferentially coupled to VLP and second, VLP may be altering the intracellular fate of the lysate proteins coupled to their surface to facilitate their immunostimulatory access to the antigen processing pathways within DC.

To confirm that conjugation of lysates to VLP enables more effective presentation, DC were fractionated into their constituent endosomal compartments and analysed for the presence of VLP or lysate-derived proteins (MART1). The resultant blots show lysates are delivered more effectively to DC, and are retained in the endosomal system for longer, when conjugated to VLP. Consistent with our previous studies defining the mechanisms
A

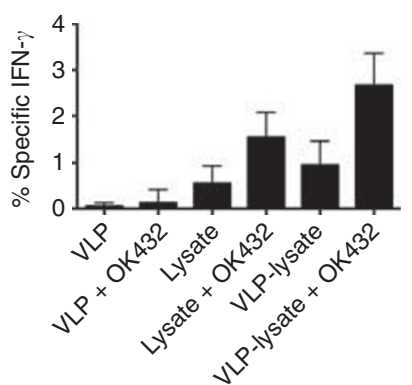

C

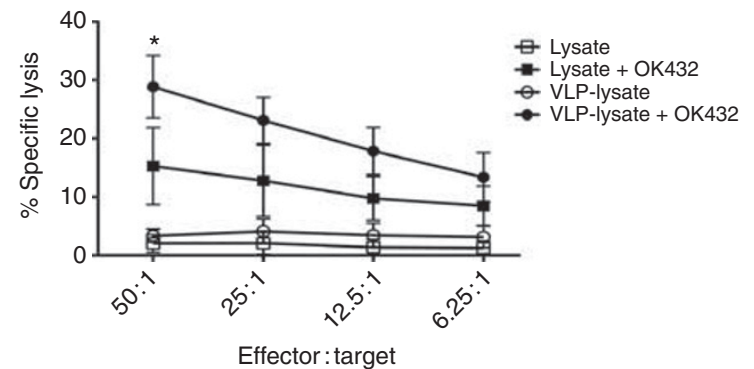

Figure 5 Activity of T cells following priming with VLP-lysate or lysates in the presence or absence of adjuvant. (A) Intracellular IFN- $\gamma$ staining within $\mathrm{CD}^{+}{ }^{+} \mathrm{T}$ cells. (B) Surface CDI07 expression on $\mathrm{CD}^{+}{ }^{+} \mathrm{T}$ cells. Bars represent specific IFN- $\gamma$ production or CDI07 degranulation on co-culture with Mel888 targets with values against irrelevant SKOV-3 targets subtracted. (C) Cytotoxicity of primed T cells against Mel888 targets labelled with ${ }^{51} \mathrm{Cr}$. Nonspecific lytic activity against irrelevant ${ }^{51} \mathrm{Cr}$-labelled SKOV-3 targets has been subtracted. Data represent mean \pm s.d. for six experiments, *Denotes statistical significance $(P<0.05)$ between VLPlysate + OK432 and lysate + OK432. 
of cross-presentation of VLP by DC, the VLP and VLP-conjugated antigen were found in early and late endosomes and lysosomes, indicating that VLP are degraded into antigenic peptides within lysosomal compartments. In contrast, when lysates were delivered alone, no MART1 was detected in any endosomal fractions, despite delivering more than double the amount of lysate protein than would be conjugated to VLP. This suggests that unconjugated lysate proteins are either not taken up to a detectable level, or that these proteins are rapidly degraded by the DC, both situations resulting in reduced cross-presentation and cytotoxic responses. Recycling endosomes were not shown to contain any VLP or lysate-derived MART1, although this is not surprising, as the degradation of VP60 or MART1 into peptides would prevent the antibodies directed against the entire protein from recognising them.

Developing effective cytotoxic T-cell responses against tumour cells is one key step towards destroying them. Ensuring naïve $\mathrm{T}$ cells are primed for activity specifically against their tumour cell target is essential to prevent autoimmunity, while priming a pool of T cells recognising a variety of tumour antigens is important for achieving maximal tumour killing and preventing escape variants. To this effect, DC pulsed with VLP conjugated to melanoma cell lysates and matured with OK432 were able to cross-prime naïve $\mathrm{T}$ cells, with associated increases in the numbers of MART1specific, IFN- $\gamma$ producing, degranulating $\mathrm{CD}^{+} \mathrm{T}$ cells. Most importantly, these expanded CTL were cytotoxic against the tumour cells from which the lysates were originally derived. In all instances, the delivery of lysates conjugated to VLP to DC resulted in more pronounced cytotoxic T-cell responses than delivery of lysates alone, despite delivering significantly less tumour antigen on conjugation to VLP.

We propose that this superior T-cell cross-priming ability conferred by VLP is likely due to more efficient uptake than cell lysates alone, leading to a greater density of tumour associated peptides being displayed on the DC surface. Virus-like particles conjugated to antigens require endosomal processing by DC before peptide display on MHC-I, whereas peptides do not. Faure et al (2009) demonstrated that sustained antigen cross-presentation was observed where antigens required processing before presentation, despite less antigen being presented directly after the initial pulse
(Faure et al, 2009). Short peptides were loaded directly onto MHC-I molecules favouring rapid presentation, but this response did not last $>24 \mathrm{~h}$. The long peptides that required processing were still being presented 3 days after initial pulsing, despite significant washing steps to remove any free peptides, a phenomenon potentially due to antigen storage compartments inside DC. This also may be true for VLP and their derivative peptides, as they are degraded in lysosomes before loading onto MHC-I that have recycled from the cell surface. Presumably, this exchange of peptide occurs in a post-lysosomal compartment that may serve as a reservoir for antigen cross-presentation over a sustained period of time. In the case of the lysates, we have shown that the addition of these to VLP prevents their inhibitory effects on DC activation. This together with increased delivery of lysate antigens to compartments where efficient cross-presentation can take place, may explain why $\mathrm{T}$ cells, which have interacted with VLP-lysate pulsed DC and matured with an adjuvant, are more effectively primed for cytotoxicity.

Tumour cell lysates have been used clinically with encouraging, though limited success (Jocham et al, 2004). The results presented here suggest that conjugation of tumour cell lysate proteins to VLP provides an excellent scaffold for the delivery of tumour-derived antigens to DC. The simple conjugation process is flexible enough to enable the addition of any tumour lysate to VLP quickly and efficiently, both key factors in transferring this antigen delivery platform into a potential clinical setting. The addition of an adjuvant to the DC is required for optimal priming of specific cytotoxic T-cell responses, although there remains scope for incorporating both antigen and adjuvant into the same VLP for more effective therapy and ease of use.

\section{ACKNOWLEDGEMENTS}

We thank Vivienne Young for her expert technical assistance. This research was supported by the Health Research Council (HRC) of New Zealand and Cancer Research UK. SY was a recipient of a Sir Charles Hercus Fellowship from the HRC and SW was a recipient of a Top Achievers' Doctoral Scholarship from the Tertiary Education Commission of New Zealand.

\section{REFERENCES}

Aguilera R, Saffie C, Tittarelli A, Gonzalez FE, Ramirez M, Reyes D, Pereda C, Hevia D, Garcia T, Salazar L, Ferreira A, Hermoso M, MendozaNaranjo A, Ferrada C, Garrido P, Lopez MN, Salazar-Onfray F (2011) Heat-shock induction of tumor-derived danger signals mediates rapid monocyte differentiation into clinically effective dendritic cells. Clin Cancer Res 17: 2474-2483

Bendz H, Ruhland SC, Pandya MJ, Hainzl O, Riegelsberger S, Brauchle C, Mayer MP, Buchner J, Issels RD, Noessener E (2007) Human heat shock protein 70 enhances tumor antigen presentation through complex formation and intracellular antigen delivery without innate immune signaling. J Biol Chem 282: 31688-31702

Dudley ME, Wunderlich JR, Yang JC, Sherry RM, Topalian SL, Restifo NP, Royal RE, Kammula U, White DE, Mavroukakis SA, Rogers LJ, Gracia GJ, Jones SA, Mangiameli DP, Pelletier MM, Gea-Banacloche J, Robinson MJ, Berman DM, Filie AC, Abati A, Rosenberg SA (2005) Adoptive cell transfer therapy following nonmyeloablative but lymphodepleting chemotherapy for the treatment of patients wth refractory metastatic melanoma. J Clin Oncol 23: $2346-2357$

Errington F, Steele L, Prestwich RJ, Harrington K, Pandha HS, Vidal L, de Bono J, Selby PJ, Coffey M, Vile RG, Melcher AA (2008) Reovirus activates human dendritic cells to promote innate antitumor immunity. J Immunol 180: 6018-6026

Fang L, Lonsdorf AS, Hwang ST (2008) Immunotherapy for advanced melanoma. J Invest Dermatol 128: 2596-2605
Faure F, Mantegazza AR, Sadaka C, Sedlik C, Jotereau F, Amigorena S (2009) Long-lasting cross-presentation of tumor antigen in human DC. Eur J Immunol 39: 380 - 390

Flohe SB, Bruggemann J, Lendemans S, Nikulina M, Meierhoff G, Flohe S, Kolb H (2003) Human heat shock protein 60 induces maturation of dendritic cells versus a Th1-promoting phenotype. I Immunol 170: $2340-2348$

Hatfield P, Merrick AE, West E, O'Donnell D, Selby PJ, Vile RG, Melcher AA (2008) Optimisation of dendritic cell loading with tumor cell lysates for cancer immunotherapy. J Immunother 31: 620-632

Hershey P, Coates AS, McCarthy WH, Thompson JF, Sillar RW, McLeod R, Gill PG, Coventry BJ, McMullen A, Dillon H, Simes RJ (2002) Adjuvant immunotherapy of patients with high-risk melanoma using vaccinia viral lysates of melanoma: results of a randomised trial. J Clin Oncol 20: $4181-4190$

Herzog GI, Solgi G, Wiegmann DS, Nienhaus C, Schrezenmeier H, Yildiz T, Lotfi R (2011) Quality of tumor lysates used for pulsing dendritic cells is influenced by the method used to harvest adherent tumor cells. BMC Res Notes 4: 153

Hong JJ, Rosenberg SA, Dudley ME, Yang JC, White DE, Butman JA, Sherry RM (2010) Successful treatment of melanoma brain metastases with adoptive cell therapy. Clin Cancer Res 16: $4892-4898$

Hovden A, Karlsen M, Jonsson R, Aarstad HJ, Appel S (2011) Maturation of monocyte derived dendritic cells with OK432 boosts IL-12p70 secretion and conveys strong $\mathrm{T}$ cell responses. BMC Immunol 12: 2 
Jocham D, Richter A, Hoffmann L, Fahlenkamp D, Zakrzweski G, Schmitt E, Dannenberg T, Lehmacher W, von Wietersheim J, Doehn C (2004) Adjuvant autologous renal tumor cell vaccine and risk of tumor progression in patients with renal-cell carcinoma after radical nephrectomy: phase III, randomised controlled trial. Lancet 21: 594-599

Kawakami Y, Eliyahu S, Sakaguchi K, Robbins PF, Rivolitini L, Yannelli JR, Appella E, Rosenberg SA (1994) Identification of the immunodominant peptides of the MART-1 human melanoma antigen recognised by the majority of HLA-A2-restricted tumor infiltrating lymphocytes. J Exp Med 180: $347-352$

Keller SA, Schwarz K, Manolova V, von Allmen CE, Kinzler MG, Bauer M, Muntweiler S, Saudan P, Bachmann MF (2010) Innate signaling regulates cross-priming at the level of DC licensing and not antigen presentation. Eur J Immunol 40: $103-112$

Kuroki H, Morisaki T, Matsumoto K, Onishi H, Baba E, Tanaka M, Katani M (2003) Streptococcal preparation OK432: a new maturation factor of monocyte-derived dendritic cells for clinical use. Cancer Immuno Immunother 52: $561-568$

Laemmli UK (1970) Cleavage of structural proteins during the assembly of the head of bacteriophage T4. Nature 227(5259): 680-685

Mehrotra S, Stevens R, Zengou R, Chakraborty NG, Butterfield LH, Economou JS, Dorsky DI, Mukherji B (2003) Regulation of melanoma epitope-specific cytolytic $\mathrm{T}$ lymphocyte response by immature and activated dendritic cells, in vitro. Cancer Res 63: 5607-5614

Mescher MF, Curtsinger JM, Agarwal P, Casey KA, Gerner M, Hammerbeck CD, Popescu F, Xiao Z (2006) Signals required for programming effector and memory development by CD8+ T cells. Immunol Rev 211: 81-92

Peacey M, Wilson S, Baird MA, Ward V (2007) Versatile RHDV virus-like particles: incorporation of antigens by genetic modification and chemical conjugation. Biotechnol Bioenginerring 98: 968 - 977

Peacey M, Wilson S, Perret R, Ronchese F, Ward VK, Young V, Young SL, Baird MA (2008) Virus-like particles from rabbit hemorrhagic disease virus can induce an anti-tumor response. Vaccine 26: 5334-5337

Qiao J, Dong Y, Pang Y-YS, Ibrahim R, Berzofsky JA, Schiller JT, Khleif SN (2006) Combined prophylactic and therapeutic cancer vaccine: enhancing CTL responses to HPV16 E2 using a chimeric VLP in HLA-A2 mice. Int J Cancer 118: $3022-3029$
Romero P, Valmori D, Pittet MJ, Zippelius A, Rimodi D, Levy F, Dutoit V, Ayyoub M, Rubio-Godoy V, Michielin O, Guillaume P, Batard P, Luescher IF, Lejeune F, Lienard D, Rufer N, Dietrich P-Y, Speiser DE, Cerottini J-C (2002) Antigenicity and immunogenicity of MelanA/MART-1 derived peptides as targets for tumor reactive CTL in human melanoma. Immunol Rev 188: $81-96$

Salcedo M, Bercovici N, Taylor R, Vereecken P, Massicard S, Duriay D, Vernel-Pauillac F, Boyer A, Baron-Bodo V, Mallard E, Bartholeyns J, Goxe B, Latour N, Leroy S, Prigent D, Martiat P, Sales F, Laporte M, Bruyns C, Romet-Lemonne J-L, Abastado J-P, Lehmann F, Velu T (2006) Vaccination of melanoma patients using dendritic cells loaded with allogeneic tumor cell lysate. Cancer Immunol Immunother 55: $819-829$

Sanchez-Perez L, Kottke T, Diaz RM, Ahmed A, Thompson J, Chong H, Melcher AA, Holmen S, Daniels GA, Vile RG (2005) Potent selection of antigen loss variants of B16 melanoma following inflammatory killing of melanocytes in vivo. Cancer Res 65: 2009-2017

Storni T, Lechner F, Erdmann I, Bachi T, Jegerlehner A, Dumrese T, Kundig TM, Ruedl C, Bachmann MF (2002) Critical role for activation of antigen presenting cells in priming of cytotoxic T-cell responses after vaccination with virus-like particles. J Immunol 168: $2880-2886$

Storni T, Ruedl C, Schwarz K, Schwendener RA, Renner WA, Bachmann MF (2004) Nonmethylated CG motifs packaged into virus-like particles induce protective cytotoxic $\mathrm{T}$-cell responses in the absence of systemic side effects. J Immunol 172: $1777-1785$

Strome SE, Voss S, Wilcox R, Wakefield TL, Tamada K, Flies D, Chapoval A, Lu J, Kasperbauer JL, Padley D, Vile RG, Gastineau D, Wettstein P, Chen L (2002) Strategies for antigen loading of dendritic cells to enhance the antitumor immune response. Cancer Res 62: 1884-1889

von Euw EM, Barrio MM, Furman D, Bianchini M, Levy EM, Yee C, Li Y, Wainstok R, Mordoh J (2007) Monocyte-derived dendritic cells loaded with a mixture of apoptotic/necrotic melanoma cells efficiently crosspresent gp100 and MART-1 antigens to specific $\mathrm{CD}^{+} \mathrm{T}$ lymphocytes. J Translation Med 5: 1-15

Win SJ, Ward VK, Dunbar PR, Young SL, Baird MA (2011) Crosspresentation of epitopes on virus-like particles via the MHC-I receptor recycling pathway. Immunol Cell Biol 89(6): 681-688

This work is published under the standard license to publish agreement. After 12 months the work will become freely available and the license terms will switch to a Creative Commons Attribution-NonCommercial-Share Alike 3.0 Unported License. 